\title{
Escola, Família e Trabalho Infantil: Subjetividade e Práticas Disciplinares ${ }^{1}$
}

\author{
Izabel Feitosa \\ Magda Dimenstein \\ Universidade Federal do Rio Grande do Norte
}

\begin{abstract}
RESUMO
O trabalho precoce está associado à pobreza e ao modo de produção capitalista que alimenta as desigualdades sociais. O presente estudo tenta considerar outros aspectos que podem estar sustentando a inserção precoce da criança no trabalho como aspectos subjetivos e disciplinares presentes nas falas de mães e professores. Realizamos esse estudo através de grupos focais envolvendo mães e professores de crianças que estudam e trabalham no cultivo das hortas em um bairro da zona rural de Natal-RN. As falas dos participantes foram tratadas segundo a perspectiva das práticas discursivas. Observou-se o quanto a disciplina está imersa nas práticas discursivas dos sujeitos. Apesar de o trabalho ser visto como algo que pode queimar uma etapa da vida ou tirar o tempo de estudar e de brincar da criança é também identificado como algo que pode livrá-las dos perigos da rua tais como vagabundagem, criminalidade e uso de drogas. O trabalho infantil é uma alternativa para a nãopermanência das crianças nas ruas. Mesmo inscritas no programa Bolsa-Escola, o trabalho dessas crianças continua sendo uma prática cotidiana, a qual vem sendo reforçada historicamente pelas instituições disciplinadoras e socializadoras como a família e a escola, aqui representadas, respectivamente, pelas mães e pelos professores.
\end{abstract}

Palavras-chave: escola; família; trabalho infantil.

\begin{abstract}
School, Family and Child Labor: Subjectivity and Disciplinary Practices

Explanations of child labor generally seek to establish a causal relationship between work and poverty, thereby limiting its focus to economic aspects and on capitalistic work production which promotes social inequality. While not overlooking these aspects, we propose to reflect upon other considerations that might be influencing the early involvement of children in the labor force. This study therefore, seeks to discuss the subjective and disciplinary aspects that are present in the discourse of mothers and school teachers who study and work in the vegetable gardens in an agricultural community located in the north zone of Natal, RN. The depositions were examined according to the discursive practice perspective. It was observed that, in general, the discipline is greatly involved in the discursive practices of the subjects. Even though child labor was seen as a mechanism that obviates the infant stage of the child and restricts a young person's ability to indulge in their studies and play, it is still considered to be an important alternative to street life. For both parents and teachers, work is something that can free the children from the risks of vagrancy, criminality and the use of drugs. It is noted that even though the children are enrolled in the SchoolGrant Program, their work in the vegetable gardens continues to be an effective practice in the context of these families. This practice has been enforced by disciplinary and socializing institutions, the family and the school, as represented in this study by the mothers and schoolteachers.
\end{abstract}

Keywords: child work, subjectivity, discipline power.

Atualmente, o trabalho infantil tem sido debatido por vários segmentos da sociedade. Esse artigo tem como meta tecer algumas reflexões acerca do tema, a partir da visão de duas instituições que estão diretamente envolvidas com a questão: a família e a escola.

A concepção de trabalho infantil que norteia esse estudo está ancorada na perspectiva adotada por Fukui, Sampaio e Brioschi (1985) e refere-se ao conjunto de atividades, realizadas por crianças, que visam possibilitar-lhes a própria sobrevivência ou a de outros. Sendo assim, considera-se trabalho uma gama de atividades que as crianças realizam, estejam ou não recebendo remuneração pelo mesmo. A Organização Internacional do Trabalho - OIT (1998) assim define trabalho infantil:

Toda actividade económica llevada a cabo por personas menores de 15 años de edad, sin importar el status ocupacional (trabajo asalaria-do, trabajo 
independiente, trabajo familiar no remunerado etc.). Ello no incluye los quehaceres del hogar realizados en su propio hogar, excepto donde los quehaceres del hogar pueden ser considerados una actividad económica - como, por ejemplo, cuando un niño dedica todo su tiempo a estos quehaceres para que sus padres puedan trabajar fuera del hogar, y ello signifique privarlo de la posibilidad de ir a la escuela (p. 3).

Gomes (1998) lida com o trabalho infantil a partir do que considera exploração. Para o autor, o trabalho infantil é explorado quando "é realizado em condições inadequadas, prejudiciais e/ou perversas; exige da criança e do jovem uma atividade bastante constante e desproporcional à suas forças, a seu estágio de desenvolvimento psicossocial; a atividade impede as brincadeiras, os jogos, o descanso e, em especial, a escolarização regular" (p. 54). Esse trabalho explorado é prejudicial à saúde, à escolarização, enfim, à vida da criança.

No Brasil, a Constituição Federal de 1988 e o Estatuto da Criança e do Adolescente - ECA (1990) proíbem qualquer trabalho aos menores de 16 anos, a não ser na condição de aprendiz - dos 14 aos 16 anos. Atualmente, existem políticas e programas de combate e erradicação do trabalho infantil. No entanto, Campos e Alverga (2001) constatam que embora tenhamos essas ações de combate, não houve um estancamento do crescimento dos índices de crianças trabalhando no setor produtivo, bem como têm surgido novas formas de inserção de crianças no trabalho evidenciando o apoio familiar. Campos e Alverga (2001) apontam ainda que os responsáveis pela formulação e implementação das propostas de erradicação do trabalho precisam considerar "a necessidade de combater os aspectos subjetivos dos sujeitos envolvidos, no sentido das crenças pessoais de patrões, famílias e crianças sobre o trabalho" (p. 228).

Nesse artigo, portanto, objetiva-se discutir sobre tais aspectos subjetivos no sentido de apreender um pouco da realidade daqueles que vivem cotidianamente envolvidos com a questão do trabalho infantil. Em função dessa escolha, se buscou mães e professores de crianças que estudam e trabalham, os quais representam as instituições disciplinadoras e socializadoras da infância: a família e a escola. Considera-se que é justamente no processo de socialização, pelo qual crianças e adolescentes passam, que a subjetividade é construída. Parte-se da suposição de que certas práticas, crenças e valores construídos em nossa sociedade em relação ao trabalho infantil estão arraigados nesses processos e instituições. Esses, por sua vez, vêm transmitindo e reforçando historicamente tais práticas e crenças.

\section{MÉTODO}

Optou-se por uma vertente qualitativa em pesquisa e pela perspectiva construcionista de compreensão dos fenômenos. De acordo com Spink e Menegon (2000), nessa perspectiva, a relação sujeito-objeto é ressignificada de modo que tanto o sujeito quanto o objeto são construções sócio-históricas e colaboradores na produção do conhecimento. Nessa pesquisa se garantiu cuidados essenciais no que diz respeito à relação com participantes: o consentimento informado, o estabelecimento de uma relação de confiança entre pesquisador e participantes e a garantia do anonimato. Quanto a este último cuidado é importante ressaltar que os nomes encontrados nos relatos dos participantes são fictícios.

\section{Participantes}

A população investigada é moradora de Gramorezinho, localidade situada numa área rural da Zona Norte da cidade do Natal/RN. Os participantes foram 08 mães e 08 professores de crianças que trabalham no cultivo de hortaliças nessa comunidade. As mães são mulheres com idade entre 27 e 47 anos, casadas, com exceção de uma que é viúva. Possuem um número grande de filhos: 04 a 09 filhos. Apenas uma tem 02 filhos. Vale salientar que as crianças estão matriculadas no programa Bolsa Escola, uma das ações que tem como objetivo eliminar o trabalho infantil.

\section{Trabalho de campo}

O trabalho de campo teve início através de contatos com a escola municipal local. Foi realizado um levantamento inicial do número de crianças que ali estudavam e trabalhavam nas hortas. Registrou-se 50 crianças: 29 meninos e 21 meninas, cuja faixa etária variava de 5 a 11 anos. Em seguida, contatou-se as famílias dessas crianças para fazer o convite para participar da pesquisa.

\section{Instrumento de pesquisa}

Utilizou-se o grupo focal como ferramenta de trabalho, o qual propiciou uma maior circulação da palavra entre os sujeitos, dando uma abertura para que eles refletissem e falassem sobre suas experiências. $\mathrm{O}$ grupo das mães foi formado por 08 mulheres e foram realizados 05 encontros, cada um com duração de uma hora. Os professores foram divididos em dois grupos 
compostos por 04 participantes cada um. Foram realizados três encontros com cada grupo, com a duração de 40 minutos. As sessões dos grupos foram gravadas e posteriormente transcritas para a análise das práticas discursivas. Como instrumento complementar foi utilizado o diário de campo, que consiste, de acordo com Minayo (1999), de um caderno em que constam as falas, informações obtidas em conversas informais e observações do cotidiano da comunidade, que digam respeito ao tema da pesquisa.

\section{Análise das práticas discursivas}

A análise das falas produzidas pelos participantes ancorou-se na abordagem teórico-metodológica da produção de sentidos no cotidiano. $\mathrm{O}$ alvo da investigação consistiu na produção de sentidos a partir das práticas discursivas. Quanto ao procedimento de análise do material de pesquisa, seu início se deu com uma imersão nas falas produzidas pelos participantes nas discussões de grupos, deixando aflorar os sentidos, sem prender os dados em categorias, classificações ou tematizações definidas a priori (Spink \& Lima, 2000). Estabeleceu-se um confronto possível entre os sentidos construídos no processo de pesquisa e aqueles presentes na literatura especializada.

\section{Família e escola: trabalho infantil, disciplina e subjetividade}

Nesse tópico, discute-se sobre a escola e a família como instituições disciplinadoras e socializadoras da infância, enfocando os aspectos disciplinares e subjetivos presentes nas falas dos sujeitos, especialmente sobre a questão do trabalho infantil. Objetiva-se apresentar os resultados de forma articulada à discussão teórica.

Há uma ligação histórica entre essas três instâncias: infância, escola e família. O estudo de Ariès (1981) retrata uma época, a Idade Média, onde não havia lugar para a escola, e a família não constituía espaço para "alimentar um sentimento existencial e profundo entre pais e filhos" (p. 231). Uma época em que a criança convivia pouco tempo com sua família de origem, pois era entregue a uma família estranha para ingressar no processo de aprendizagem, através do qual a criança adquiria conhecimentos, experiências e valores no convívio direto com os adultos.

No século XVII, a partir da compreensão da particularidade da infância, a família e a escola, juntas, retiraram a criança do mundo dos adultos. A escola se tornou uma instituição complexa e o local por excelência da educação. Concomitantemente, ocorreram transformações na realidade da família: "é como se a família moderna tivesse nascido ao mesmo tempo (...) que o hábito geral de educar as crianças na escola" (Ariès, 1981, p. 232). A família assume um rigor moral na educação das crianças, uma preocupação de isolá-las do mundo dos adultos e de vigiá-las. Essa preocupação com a criança está enraizada na família moderna, caracterizada pelas relações afetivas intensas entre pais e filhos, pelos cuidados especiais dedicados às crianças, que não mais são abandonadas aos cuidados de uma outra família, bem como pela privacidade do lar.

Ariès (1981) afirma que a escola se tornou espaço de vigilância e disciplina, sendo que o seu estabelecimento foi o que possibilitou a transformação da escola medieval em colégio moderno.

(...) a criança deixou de ser misturada aos adultos e de aprender a vida diretamente, através do contato com eles (...) a criança foi separada dos adultos e mantida à distância numa espécie de quarentena (...) essa quarentena foi a escola, o colégio. Começou-se então um longo processo de enclausuramento das crianças (como dos loucos, dos pobres e das prostitutas) que se estenderia até nossos dias, e ao qual se dá o nome de escolarização (p. 11).

Para Foucault (1977), o que marcava esse momento histórico? Para esse autor tratava-se de exercer poder sobre os homens, de controlar suas relações, de construir uma sociedade disciplinar. Em função disso, processos e instituições de individualização começaram a ser constituídos no sentido de marcar exclusões: asilos psiquiátricos, penitenciárias, casas de correção, escolas, hospitais e as instâncias de controle individual de um modo duplo: adulto - criança; louco - não louco; doente - são; perigoso - inofensivo; normal anormal. Segundo o autor, o poder disciplinar tem na norma sua referência e essa terá o adulto, não louco, inofensivo, normal, como paradigma, como modelo. Portanto, a doença, a loucura, a delinquiência e a criança, passam a ser alvos do poder disciplinar.

Conforme Foucault (1996), a invenção da disciplina implicou numa vigilância dos indivíduos. Donzelot (1986), em “A polícia das famílias”, seguindo uma perspectiva foucaultiana, aponta as diferentes estratégias oferecidas pelo Estado e pela medicina no intuito de intervir nas classes sociais. Na classe burguesa, a intervenção voltou-se para uma proteção moral e maior liberdade física da criança. A infância passa a ser caracterizada por uma liberdade protegida e por uma vigilância discreta. Já nas camadas popula- 
res, as intervenções ocorriam no sentido de conter as liberdades, o abandono das crianças e de impedir a vagabundagem das mesmas. Observa-se, aqui, uma infância caracterizada por uma liberdade vigiada.

Esse sentido de vigilância sobre a infância foi identificado nas falas dos participantes da pesquisa. Vigilância que está presente no espaço do trabalho nas hortas. O espaço da rua representa uma ameaça por ser um espaço em que a criança não está sob o olhar da família. A horta aparece, então, como uma extensão da casa e da escola, como espaço de vigilância e de disciplina. Alguns relatos de mães e professores indicam isso:

A gente levando pra horta, a gente tá vendo o que eles tá fazendo (...) (Relato M).

(...) eu vejo o trabalho, por exemplo, do menino que trabalha na horta, porque geralmente ele trabalha com quem? Ele trabalha com a família. Então a família sabe o horário da escola, isso e aquilo, geralmente, é a família. É diferente do menino que vende picolé na rua, que às vezes o menino estuda à tarde e quando cuida o menino, 12 horas tá na rua. E ali não tem controle, não tem a vista dos pais pra presenciar o que ele tá fazendo. (...). Esses meninos daqui, eles trabalham em hortas, certo. É um trabalho, geralmente, vigiado pela família e aí onde a gente também vê essa questão do nível de marginalização, marginalização no sentido de desvio para determinadas condutas sociais. A gente não vê muito, aqui nessa comunidade, porque tem a vigilância da família. Mas, ao mesmo tempo que tem esse ponto positivo da vigilância da família, a gente já vê esse outro aspecto, que de qualquer maneira essa criança (pausa) tá perdendo (ri) um tempo, uma coisa importante na vida dela (Relato prof. $R$.).

A fala do professor R. é interessante porque aponta dois aspectos importantes da questão do trabalho das crianças presente, em geral, nas falas dos participantes. O lado positivo do trabalho consiste no fato das crianças estarem sob vigilância permanente da família. $\mathrm{O}$ que permite à mesma um maior controle sobre as crianças, evitando o "desvio para certas condutas sociais". O aspecto negativo seria a perda de coisas importantes na vida das mesmas, como por exemplo, o tempo de brincar, o tempo de estudar e até mesmo uma etapa na vida como a infância. Apesar dessa realidade, o trabalho é indiscutivelmente visto pelos participantes, tanto professores quanto mães, como algo bom para a vida das crianças.

No decorrer das sessões de grupo focal com os professores há sempre um julgamento entre o que é certo e errado em relação ao trabalho das crianças na horta. Tais participantes estabelecem limites quanto à exploração e à exposição ao agrotóxico. A fala de uma professora é bastante elucidativa:

(...) Pra mim o errado é ele deixar de freqüentar a escola para trabalhar, entendeu? Se fosse um horário oposto... (Relato prof ${ }^{\mathrm{a}}$. Rs).

O que ela aponta nessa fala? Que é aceitável uma criança trabalhar. O problema reside quando o mesmo é realizado no horário da escola. Ou seja, embora apontem a sobreposição de horário entre trabalho e estudo como algo problemático, em nenhum momento, para os participantes, o trabalho em si aparece como algo que deva ser proibido ou combatido. $\mathrm{Ou}$ seja, o trabalho comparece como parte da infância. Como relata a professora K., o trabalho é algo sobre o qual não se pode abrir mão:

(...) Mas eu, sinceramente, eu sou a favor da responsabilidade. (...) Pra mim, a horta em si, a responsabilidade é bom. Não abro mão. Tudo bem, nada de exagero, não um trabalho escravo, mas que uma responsabilidade da criança, desde cedo (...) que a gente vê tanta coisa, tanta criança solta por aí, por quê?? Porque não tem responsabilidade dentro de casa. Ficam na rua. Ficam na rua aprendendo o quê? Boa coisa não é (...) (Relato prof ${ }^{a}$. K.).

Vale salientar que são as mães que assumem a responsabilidade de conduzir suas crianças ao espaço da horta cotidianamente. Esse papel que é assumido por elas remonta à influência que os higienistas tiveram no Brasil, criando uma nova organização doméstica, redefinindo os papéis da família e da infância, dando à mulher um papel de destaque no cuidado dos filhos (Costa, 1983). Segundo elas:

A mãe vai trabalhar, deixa eles em casa. Eles vão pra rua, né? A gente vai trabalhar, leva eles (Relato J).

(...) Aí eles, às vezes, ia mais o pai, mas se eles quiser fazer faz, se num quiser, também, num tá nem aí. (...) Só vão se eu obrigar mesmo e mandar eles ir. É porque não gostam mesmo. (...) O теи (o marido) diz assim: 'Oh, manda eles vim fazer', porque sabe que se eu mandar eles vem (Relato P).

Os meus se eu mandar fazer eles fazem. O pai também é assim que nem MC tá dizendo, ele não obriga ninguém a fazer nada, não. Ele manda fazer, se o menino fez, bem. Se não fez, ele (o pai) vai fazer. (...) Mas eu, não. Eu fico em casa, mas eu passo a 
ordem: 'Olhe, vá embora, você vá trabalhar porque tem que ir (Relato A).

Conforme Donzelot (1986), a estratégia de familiarização nas classes populares na segunda metade do século XIX, teve como suporte principal a mulher, a quem cabia a função de tirar o homem do cabaré e as crianças das ruas. Ela recebia instrumentos e aliados como a instrução primária, ensino da higiene doméstica, dentre outros. O espaço da casa tornou-se um espaço de vigilância mútua, no qual havia um espaço destinado aos pais, separado dos filhos e que possibilitasse "vigiá-los em suas ocupações sem serem observados na sua intimidade" (p. 44). A habitação se transformou, em relação ao controle das crianças, numa peça complementar à escola. $\mathrm{O}$ espaço familiar e o escolar, portanto, são configurados por Donzelot (1986) como espaços de maior vigilância das crianças, para os quais as mesmas deveriam ser dirigidas. Segundo ainda esse autor, o interesse pela infância diz respeito ao pensamento da época, que pretendia combater as desordens, a imoralidade e a insurreição, começando pela base. Daí a necessidade de uma vigilância severa da educação nesse período da vida. A difusão da norma pelo corpo social se deu através da escola, a qual se configurou como a solução para os problemas que ameaçavam a ordem pública.

Autores como Eizirik (1993), Rosa (1997), Singer (1997) e Corazza (2000), também sob uma perspectiva foucaultiana, discorrem sobre a produção de um sujeito através de mecanismos de poder. Todos estes autores tratam do poder como prática de sujeição, alguns enfocando somente a escola, outros, a escola e a família como instituições onde se exerce tal prática. Eizirik (1993) afirma que o tema central da investigação de Foucault não é o poder, mas o sujeito que está imerso nas relações de poder, além de relações de produção e significação. Sujeito para Foucault é:

(...) uma palavra que tem dois significados - o sujeito submetido a outro através do controle e a dependência, e sujeito atado à sua própria identidade pela consciência ou conhecimento de si mesmo. Ambos os significados sugerem uma forma de poder que subjuga e submete (Foucault, 1979, citado por Eizirik, 1993, p. 37).

No interior das instituições disciplinares como a família e a escola, dá-se o investimento do poder, instauram sobre o corpo da criança um regime disciplinar a fim de obter a sujeição dos corpos. Nessas instituições, preparam-se as crianças "para aceitar um regime de subserviência passiva, obediência hercúlea às normas e padrões estabelecidos que primam pela manutenção da ordem" (Rosa, 1997, p. 247). Em relação ao trabalho infantil nas hortas, nesse espaço está presente o regime disciplinar primando a ordem. Algo exercido tanto pelas mães quanto pelos professores.

A família e a escola ao se encarregarem da educação da criança conduzem suas ações de modo que a coerção passe pela norma, pela disciplina. No processo da ação socializadora, educativa, essas duas instituições atuam como agências transmissoras da cultura. Lembrando Durkheim (1978), as crenças e práticas que nos são transmitidas pelas gerações anteriores, são absorvidas "porque, sendo ao mesmo tempo uma obra coletiva e uma obra secular estão investidas de uma autoridade que a educação nos ensinou a reconhecer e a respeitar" (p. 91). Para esse sociólogo, os pais e os professores estão como os representantes e intermediários da educação, de uma coação que a criança recebe para se constituir como um ser social. É uma coação permanente, pois todos estão obrigados a ser, a estar na lei.

(...) toda educação consiste num esforço contínuo para impor à criança maneiras de ver, de sentir e de agir às quais ela não teria chegado espontaneamente. Desde os primeiros tempos da sua vida a coagimos a comer, a dormir e a beber a horas regulares. Coagimo-la à limpeza, à calma, à obediência; mais tarde, coagimo-la a ter em conta os outros, a respeitar os usos, as conveniências, a trabalhar etc. etc. Se com o tempo a coação deixa de ser sentida, é porque fez nascer hábitos e tendências internas que a tornam inútil, mas que só a substituem porque derivam dela (p. 89).

A partir dessa reflexão de Durkheim é possível enfocar um aspecto da pesquisa que diz respeito à presença de uma educação para as crianças voltada para o trabalho, ou seja, tratamos de uma infância perpassada pelo trabalho. As mães demonstram claramente uma preocupação em conduzir suas crianças desde cedo para o trabalho nas hortas. Sobre isso foi dito:

A gente leva quando é pequeno. O meu, levo com dois anos já pra... ele não vai trabalhar, ele já fica mais com a gente na horta. Ele fica brincando lá. A gente trabalhando e eles brincando. Aí quando começa a trabalhar (pausa) com seis anos ele já começa a limpar um pouquinho, vai aprendendo. $O$ meu agora tá com 12 anos ele já faz aguação, já faz mais coisa que o mais pequeno (Relato Ct.).

Todas as mães que participaram do estudo tiveram uma infância de trabalho. Começaram a trabalhar com 
a idade entre 5 e 7 anos. Uma dessas mulheres perdeu a mãe muito cedo e vivia com o pai que a levava para o trabalho: "Com 5 ou 6 anos eu ia para o roçado. Dormia nos campos, no sisal. Eu achava horrivel. (...)" (Relato C.). Conta que o pai era uma pessoa muito doente, tinha asma, precisava comprar remédios e que ela sabia que tinha que ajudar. Relata que, às vezes, parecia ficar meio bêbada com o cheiro forte do sisal. As pessoas do grupo não sabiam o que era sisal, nem sabiam dessa parte da vida dela. Ela pensou que não iria falar desse passado, o qual retrata como algo muito triste e muito sofrido para ela.

(...) Por causa que quando eu era também pequena... eu também não achava bom, quando mandavam eu fazer uma coisa, forçado. Eu que era forçado. Eu também ficava me maldizendo, reclamando também, aí, era ruim, eu achava que era ruim, eu acho que eles também acham a mesma coisa (...) (Relato C.).

Elas falam do trabalho como uma obrigação, sendo uma experiência que ninguém contestava: "Não podia se queixar, se se queixasse apanhava. (...) Tinha que fazer, né? Ou fazia ou apanhava. (...)" (Relato Cr). A maioria administrava o seu próprio dinheiro que era para se manter, comprar roupa etc. As que trabalharam em horta na infância falam de uma época em que para regar as hortas tinham que carregar água num balde, pois não havia mangueira. Falam de uma intensa jornada de trabalho:

Lá em casa eram 8 mulheres e 3 homens. Lá em casa os homens eram mais preguiçoso que a gente. A gente, mamãe botava mais a gente pra fazer o serviço deles e ainda ia pra horta. Trabalhava em horta... era pra torá... era pra tudo mesmo (Relato Ct.).

A gente tinha obrigação na horta e tinha obrigação em casa quando chegava em casa a tarefa da gente era comprida. Uma pra lavar a louça e a outra pequena pra enxugar. Aí uma mais velha ia casando e ia ficando a mais nova no serviço dela. Trabalhava na horta e trabalhava em casa (Relato Ct.).

Para algumas, a infância de trabalho foi uma vivência tão sofrida que faz com que não desejem o mesmo para seus filhos: "Mas era quase uma escravidão. Eu mesma nem... eu nem boto pro meu filho, porque eu não quero, não faço o que papai fazia comigo" (Relato C.). Entretanto, a despeito disso, mantém-se uma educação para e pelo trabalho. A professora R. mencionou o trabalho das crianças nas hortas como algo presente na cultura dessas famílias, sendo transmitido aos filhos como um ensinamento. Para as mães, o trabalho na horta é o único capital cultural que elas dispõem para transmitir aos filhos.

(...) e a gente aprendeu o que ela (a mãe) levou pra gente, a gente aprendeu com ela (Relato B.).

(...) Eu não tenho outra coisa a oferecer, o que eu tenho a oferecer a eles, só é o trabalho. É o que eu fiz, é o que eu sei fazer, é o que eu posso fazer e posso ensinar a eles. (...) E porque é só o trabalho que a gente tem mesmo e o que a gente pode ensinar (Relato C.).

(...) É tipo um ensinamento, a gente leva eles pra horta. Num é pra. eles ir pra o lucro ser maior. É o ensinamento pra eles aprender o que a gente sabe, pra mim é assim. Num vai fazer diferença no dinheiro, não (Relato J.).

Portanto, o trabalho é uma prática que vem sendo transmitida de geração em geração, sendo parte integrante de um tipo muito particular de infância, indicando a impossibilidade de pensá-la de forma naturalizada e a-histórica. Estamos falando de uma infância pertencente a uma determinada classe social, que vem reproduzindo, através de gerações, uma educação voltada para o trabalho. Thompson (1987) apresenta uma visão de classe social que pode contribuir com a discussão. $\mathrm{O}$ autor entende classe como uma formação tanto cultural quanto econômica. Trata da experiência de classe e da consciência de classe. A primeira é "determinada, em grande medida, pelas relações de produção em que os homens nasceram ou entraram involuntariamente" (p. 10). Já a segunda diz respeito à forma como essas experiências são tratadas em termos culturais: "encarnadas em tradições, sistemas de valores, idéias e formas institucionais" (p. 10).

Para tratar do trabalho infantil é preciso nos remeter às instituições responsáveis pela socialização da criança, instituições que interiorizaram valores e crenças sobre o trabalho infantil produzidos na nossa cultura. Nas falas dos participantes há uma crença de que o trabalho das crianças pode livrá-las dos perigos da rua, das drogas, enfim, das mazelas sociais. Um trecho de uma sessão das mães pode ilustrar isso:

(...) porque no caso que era um tio meu, que o pai dele mimava ele demais. Ele um rapaizão com 17 anos. Ele morava com a gente, aí eu trabalhava, aí quando papai dizia: 'bota fulano pra trabalhar!'. Aî o pai dele: 'Não, meu filho num vai trabalhar, não porque é muito novo, nunca pegou em enxada, num sei o quê'. Quando pensou que não, ele já vivia na 
marginalidade e quando matou gente, foi preso. Num foi pior pra ele? Num era melhor ter ensinado pra ele a trabalhar?

- Você acha que o trabalho ajuda nessas coisas? (entrevistador)

Ajuda! (...). A gente é só aquela... aquela escola e o resto do dia é vago. A gente tem que botar eles pra fazer alguma coisa, porque se a gente deixar, vai ser desse jeito. Porque tem exemplo que a gente vê, aí pronto. Tem que botar pra trabalhar, porque pelo menos eles tão ocupando a cabeça em alguma coisa. Porque como eu tenho a dizer, mente desocupada é (não audivel) do diabo. Porque você num tem nada pra fazer, aí você procura fazer alguma coisa pra se ocupar (Relato M).

Observa-se nessa investigação que as mães vêm reproduzindo os sistemas de valores e as tradições encarnadas em relação ao trabalho presentes no grupo social ao qual pertencem. Isso é o que Bourdieu, segundo Brandão (2000), chama de habitus. Esse autor, em artigo intitulado "Família e escola na constituição da subjetividade", esboça uma síntese sobre a ação que a família e a escola têm na construção da subjetividade da criança como forma peculiar de estar e agir no mundo social. Habitus, conforme Brandão (2000) trata das disposições duráveis para agir, pensar, sentir e valorar de uma determinada maneira no mundo social, algo que se inscreve no corpo social e se manifesta no andar, sentar, comer, beber, nos códigos lingüísticos e nos "gostos de classe". É a cultura inscrita no corpo social, no próprio corpo dos sujeitos.

Para Brandão (2000), a família e a escola desempenham, pois, um papel fundamental na formação dos habitus. É no processo de socialização que percepções, sentimentos, pensamentos, desdobram-se sobre as ações das crianças e, progressivamente, constituem a subjetividade. As subjetividades são construídas num processo permanente de reapresentar-se no jogo do convívio social com uma bagagem de disposições "herdadas" das práticas sociais familiares e escolares. Portanto, estas instituições interferem cotidianamente na constituição dos habitus necessários ao enfrentamento das exigências da vida social.

No tocante a nossa população investigada, qual é a bagagem de disposições que essas crianças "herdam"? As falas das mães e dos professores apontam para um modelo norteador de infância cuja referência é o trabalho. E é esse modelo, presentificado em suas próprias vidas, que elas acabam reproduzindo:
Queria que eles tivessem um futuro melhor, que estudasse bastante, que se formasse, tivesse um bom emprego. Eu acho difícil, porque sempre os filhos se espelham nos pais. Aí vê a gente nessa mormaça e toda vida foi assim, nasceu, cresceu... aí pronto! Já vai passando isso pra eles, aí pronto. (...) (Relato B.).

É porque embarca, assim, naquela imagem do pai. O pai é a pessoa mais importante, ele é o dono da horta. Então, o filho, ele se espelha também naquela questão da autoridade do pai. E aquela autoridade do pai num vai precisar de escola, não. Vai precisar plantar a horta, saber vender o que ele tira da horta pra poder manter a família (Relato prof. $R$.).

Observa-se, portanto, a implicação da família e da escola em relação à infância e o quanto mães e professores, participantes desse estudo e representantes destas instituições, têm reproduzido práticas construídas na nossa cultura em relação ao trabalho infantil.

\section{CONSIDERAÇÕES FINAIS}

No Brasil, durante décadas, a criança pertencente ao universo da pobreza foi encaminhada ao trabalho encontrando respaldo em todo o corpo social. A partir dos anos 90 surgem as políticas para combater o trabalho infantil com estratégias de prevenção e erradicação. No entanto, há uma distância enorme entre o que é pensado e decidido em termos de políticas e as realidades vividas pelas famílias, que não só apóiam, mas, muitas vezes, impõem a entrada das crianças no trabalho. Conforme Ferreira (2001):

Essas estratégias têm padecido de lacunas importantes de conhecimento nos vários lugares onde o trabalho infantil se apresenta, impedindo que as iniciativas sejam mais qualificadas e alcancem maior eficácia tanto na eliminação quanto na estruturação de estratégias preventivas (p. 214).

O estudo realizado na localidade de Gramorezinho desvenda algumas vulnerabilidades das ações e políticas de combate ao trabalho infantil. Primeiramente, a Constituição Federal e o Estatuto da Criança e do Adolescente ao proibirem "qualquer" trabalho aos menores de 16 anos abrem possibilidade para malentendidos. Pois, uma vez que não diferencia que tipo de prática deve ser proibida, constrange várias famílias que utilizam o trabalho de suas crianças como forma de aprendizagem e socialização. São os casos de abuso e de exploração da mão-de-obra infantil que devem ser proibidos e erradicados. Essa distinção é impor- 
tante, segundo Silva, Neves Júnior e Antunes (2002), pois

(...) determinados tipos de trabalho podem contribuir para o desenvolvimento de habilidades e socialização das crianças e adolescentes, conquanto não interfiram na educação escolar, na recreação e no repouso. É o caso, por exemplo, de trabalhos realizados em ajuda aos pais nos afazeres domésticos, no campo, nas lojas, entre outros, ou sob supervisão de entidades públicas ou privadas, voltados ao aprimoramento profissional (p. 32).

Em segundo lugar, a estratégia dos programas de combate e erradicação ao trabalho infantil, qual seja, a de conceder uma complementação na renda familiar, por sinal insuficiente para suas necessidades, e conseguir o apoio dessas famílias para retirarem suas crianças do trabalho, mantendo-as na escola, parece muitas vezes fracassar. No tocante à complementação da renda, a questão fundamental para essas mães não diz respeito ao recebimento um valor para tirar os filhos do trabalho, mas sim, dispor de oportunidades para seus filhos: serviços públicos para os quais as crianças pudessem ser encaminhadas para aprender uma profissão, ter um ofício na vida. Ou seja, o problema reside na falta de políticas públicas consistentes que proporcionem a inclusão social dessas camadas da população. A criança que trabalha, na sua maioria, faz parte de uma família que vive em condições de pobreza e que não pode prescindir do trabalho dos filhos. Além disso, são famílias que não usufruem de equipamentos de suporte social tais como creches ou instituições profissionalizantes. Em outras palavras, o trabalho infantil está vinculado, em parte, aos processos de desigualdade existentes no país, ao crescimento da pobreza e às políticas pouco eficientes no enfrentamento da iniqüidade social. Mas, para além do econômico, existem outros fatores que contribuem para a manutenção do trabalho infantil.

Ao lançar uma escuta voltada às mães e aos professores tentando apreender os sentidos que atribuem ao trabalho infantil, se encontram sutilezas importantes vividas no cotidiano daquela realidade que se tornam também obstáculos às ações de combate ao trabalho infantil. Sutilezas que dizem respeito aos aspectos subjetivos e disciplinares presentes nas falas dos sujeitos que lidam diretamente com as crianças. Isso possibilitou uma análise mais aprofundada do fenômeno, derivando algumas reflexões a mais.

A partir de Foucault (1996), considera-se que no espaço do trabalho são constituídas as estruturas de micro-poderes. Para as mães, é no espaço do trabalho nas hortas que elas exercem o poder disciplinar, im- plicando em vigilância, em ocupação do tempo, em controle sobre seus filhos. O trabalho das crianças nas hortas cumpre, portanto, uma função disciplinar. Estar no trabalho impede a circulação dessas crianças no espaço da rua, o qual aparece imbuído de perigo e risco. Há uma crença geral por parte dos participantes de que o trabalho é o que livra as crianças dos perigos que a rua e a ociosidade podem trazer, tais como a criminalidade, a vagabundagem, o uso e o tráfico de drogas etc. O trabalho aparece nas falas de alguns professores, como algo do qual não se pode "abrir mão". Para as mães que participaram do estudo, o trabalho é o único capital cultural que elas possuem para transmitir às suas crianças. Em relação ao campo de investigação, constata-se, portanto, que algumas crenças e práticas sobre o trabalho infantil, permanecem arraigadas e interiorizadas nas mães e professores, representando as instituições responsáveis pela socialização das crianças. Mudanças nas concepções e práticas relativas ao trabalho infantil implicam a resignificação desses pilares em toda a sociedade. Entretanto, como operar nesse sentido se estamos inseridos em uma cultura que se sustenta por meio da produção de uma população underclass associada ao crime, perigo, violência e desintegração social e onde o trabalho é um poderoso dispositivo de conversão, controle e construção do cidadão honesto, individualizado, trabalhador e individualista? Tal categoria utilizada por Wacquant (2001, citado por Passetti, 2002)

(...) descreve e designa uma subcultura feroz, com concentração de desvios de comportamento entrelaçados a patologias. Distingue pobres virtuosos de maus pobres, os disfuncionais com desemprego perpétuo consumindo recursos crônicos de ajuda social, desorganização conjugal, anomia sexual, fracasso escolar, tráfico e consumo de drogas, encarceramentos, delinqüência de rua e criminalidade violenta (p. 16).

Portanto, se reconhece o fundamento técnicodisciplinar do trabalho infantil na medida em que tem como função básica assegurar o status quo e a reprodução do capital, favorecer a conformidade desses grupos sociais com sua própria condição (a de que "naturalmente" lhes falta algo) a partir da fabricação de um corpo/sujeito dócil-útil, que "acredita" que o trabalho, mesmo explorado, é a possibilidade de impedir a manifestação do "vírus da delinquiência" que lhe é constitutivo, o qual pode se expressar ao menor vacilo de sua eterna vigilância. As políticas e programas de erradicação e controle do trabalho infantil são, portanto, medidas compensatórias para aqueles aspi- 
rantes a cidadão, considerados em "situação de risco". Nesse sentido trazem arraigados o controle e a disciplina, bem como uma promessa (cidadania plena) difícil de ser materializada no cotidiano de crianças e adolescentes pobres e trabalhadores.

\section{REFERÊNCIAS}

Ariés, P. (1981). História social da criança e da família. Rio de Janeiro: Editora Guanabara Koogan S.A.

Brandão, Z. (2000). Família e escola na constituição da subjetividade. Em S. J. Souza (Org.), Mosaico: imagens do conhecimento (pp. 96-101). Rio de Janeiro: Rios Ambiciosos.

Campos, H. R. \& Alverga, A. R. (2001). Trabalho infantil e ideologia: contribuição ao estudo da criança indiscriminada na dignidade do trabalho. Estudos de Psicologia, 6(2), 227-233.

Corazza, S. M. (2000). História da infância sem fim. Ijuí: Ed. Unijuí.

Costa, J. F. (1983). Ordem médica e norma familiar. Rio de Janeiro: Edições Graal.

Donzelot, J. (1986). A polícia das famílias. Rio de Janeiro: Edições Graal.

Durkheim, E. (1978). As regras do método sociológico. São Paulo: Abril Cultural.

Eizirik, M. F. (1993). As relações entre saber e poder nas diversas dimensões da escola. Em E. P. Gressi e J. Bordin (Orgs.), A paixão de aprender (pp. 35-41). Petrópolis: Vozes.

Estatuto da Criança e do Adolescente (1990). Brasília: Ministério do Trabalho, Secretaria de Fiscalização do Trabalho.

Feitosa, I. C. N. (2003). Trabalho infantil na agricultura: sentidos produzidos pelas mães e pelos professores. Dissertação de Mestrado não publicada. Programa de Pós-Graduação em Psicologia, Universidade Federal do Rio Grande do Norte, Natal.

Ferreira, M. A. F. (2001). Trabalho infantil e produção acadêmica nos anos 90: tópicos para reflexão. Estudos de Psicologia, 6(2), 213-225.

Foucault, M. (1977). Vigiar e punir: nascimento da prisão. Petrópolis: Vozes.

Foucault, M. (1996). Microfísica do poder. Rio de Janeiro: Edições Graal.
Fukui, L. F. G.; Sampaio, E. M. S. \& Brioschi, L. R. (1985). A questão do trabalho infantil na grande imprensa paulista na década de 70. Revista Brasileira de Estudos Pedagógicos, 66(152), 28-46.

Gomes, J. V. (1998). Vida familiar e trabalho de crianças e de jovens pobres. Paidéia, 6, 45-61.

Minayo, M. C. S. (1999). O desafio do conhecimento: pesquisa qualitativa em saúde. São Paulo: Hucitec; Rio de Janeiro: Abrasco.

Organização Internacional do Trabalho (1998). El trabajo infantil: Lo intolerable en el punto de mira. Conferencia Internacional del Trabajo, 86 reunión. Informe VI, parte 1. Genebra.

Passetti E. (2002). Cartografias de violências. Serviço Social \& Sociedade. Ano XXIII, 70, 5-43.

Rosa, R. M. (1997). Subjetividade produzida: poder e disciplina em uma problematização foucaultiana. Em D. Baptista (Org.), Cidadania e subjetividade - novos contornos e múltiplos sujeitos (pp. 229-290). São Paulo: Imaginário.

Silva, J. L. T.; Junior, L. F. N. \& Antunes, M. M. (2002). Trabalho infantil: realidade, diretrizes e políticas. Em M. E. Marques; M. A. Neves \& A. C. Neto (Orgs.), Trabalho infantil: a infância roubada (pp. 17-41). Belo Horizonte: PUC Minas, Instituto de Relações do Trabalho.

Singer, H. (1997). República de crianças: sobre experiências escolares de resistência. São Paulo: Hucitec.

Spink, M. J. \& Lima, H. (2000). A pesquisa como prática discursiva: superando os horrores metodológicos. Em M. J. Spink (Org.), Práticas discursivas e produção de sentidos no cotidiano: aproximações teóricas e metodológicas (pp. 93-112). São Paulo: Cortez.

Spink, M. J. \& Menegon, V. M. (2000). Riscos e visibilidade: a explicitação dos passos da interpretação. Em M. J. Spink (Org.), Práticas discursivas e produção de sentidos no cotidiano: aproximações teóricas e metodológicas (pp. 63-92). São Paulo: Cortez.

Thompson, E. P. (1987). A formação da classe operária. Rio de Janeiro: Paz e Terra.

Enviado: 06/08/2004 Revisado: 01/11/2004 Aceito: $11 / 11 / 2004$

\section{Nota:}

${ }^{1}$ As reflexões aqui presentes fizeram parte da pesquisa de Mestrado realizada por Feitosa (2003) no Programa de Pós-Graduação em Psicologia da UFRN, e intitulada "Trabalho infantil na agricultura: sentidos produzidos pelas mães e pelos professores".

\section{Sobre as autoras:}

Izabel Feitosa: Professora substituta do curso de Graduação de Psicologia da Universidade Federal do Rio Grande do Norte. Mestra em Psicologia - Endereço Eletrônico: izabelsec21@yahoo.com.br.

Magda Dimenstein: Coordenadora do Programa de Pós-Graduação em Psicologia da Universidade Federal do Rio Grande do Norte. Endereço para correspondência: UFRN, CCHLA, Depto. de Psicologia, Campus Universitário, Lagoa Nova, 59078-970 Natal/RN Endereço Eletrônico: magda@ufrnet.br. 